\title{
THE BUILT ENVIRONMENT AS A COMPLEX SYSTEM
}

\author{
C.E. CLOETE \\ Department of Construction Economics, University of Pretoria, South Africa.
}

\begin{abstract}
The lack of a recognized theoretical disciplinary base for the built environment has been noted on a number of occasions. The field holds the promise of being interdisciplinary, but requires the development of a common epistemological construct. It has been proposed that a unified theory of the built environment may require that the built environment be understood as a complex social-ecological system. It will argued, however, that the challenge is more fundamental; that development of an adequate model would require convergence of the ideas of interdisciplinarity and complexity, with concomitant epistemological as well as ontological considerations. The application of whole-system theory to the built environment is explored with special reference to the identification of boundaries and modularities in different domains and the implications for a taxonomy of the built environment. The development of a theoretical base for the field as a whole would facilitate axiological decision-making in the built environment and also inform both curriculum design and research strategy in the subject area.

Keywords: boundaries, built environment, complex system, criteria, entities, methodology.
\end{abstract}

\section{INTRODUCTION}

The lack of a recognized theoretical disciplinary base for the built environment impedes the development of the built environment as an academic discipline. Attempts to formulate a unified theory of the built environment include instrumentalism [1] as well as the proposal that the built environment be understood as a complex social-ecological system, where multiple-related metabolisms interact at different scales [2]. Apart from providing a framework for investigating the impact of the built environment [3-5], the desired framework would be useful for providing a taxonomy for the built environment and the classification of information about construction [6-8].

It is proposed that this endeavor requires the development of a common epistemological construct, to be found in application of whole-system theory to the built environment. The argument will be structured by considering (i) the recognition of entities and the nature of systems (in particular complex systems), (ii) complexity and interdisciplinarity, and (iii) the epistemological implications of considering the built environment as a complex system.

\section{THE NATURE OF SYSTEMS}

\subsection{Recognition of entities}

To consider something implies the idea of distinction. To be able to think of or perceive it at all, it must be distinguishable from what it is not. We cannot indicate it without drawing a distinction. To draw a distinction (to indicate) is to let "that which is being considered" stand out from "that which is not being considered". 
A distinction is drawn according to some distinguishable criterion. The fact that we draw a distinction according to some distinguishable criterion is stressed because one quite often distinguishes something according to different criteria. A building may be a functional space, an aesthetic object, an investment, etc. The variety of distinguishable criteria is bounded only by man's imagination.

An entity is distinguished from its environment according to some distinguishing criterion. What is considered to be the system and what the environment, will therefore vary according to the criterion or criteria of distinction. The system that is the focus or unit of attention at any given point in time can be called the focal system.

After the initial identification, the entity is then often considered in the light of further distinguishing criteria. A building, identified initially by, say, localization in space, may also be considered as a consumer of electricity, an object of beauty or a source of tax. Similarly, a construction element is a major component, assembly, or "construction entity part which, in itself or in combination with other parts, fulfills a predominating function of the construction entity" [8].

In each case interest is shifted to a different environment and the relationship of the entity under consideration to that environment.

After any one criterion of distinction has been applied to identify the entity under consideration, application of other criteria may also lead to the distinction of other entities within the original entity. Let us call the entities so distinguished the elements (synonyms: parts, members) of the entity under consideration, and let us call an entity which is composed of elements a set. The notion of set is primitive and synonyms which might be used are "class", "collection" or "aggregate".

\subsection{Systems}

If the elements interact with each other, the set is called a system. System constituents are coupled to each other via some kinds of relations, they are not mere aggregates like sand grain piles. A system is a complex whole with a set of components interacting with each other. Changes in any part of a system affect the whole system and parts of a system are affected by changes in the system as a whole. The higher the degree of interdependence of the elements, the higher the degree of 'wholeness' of the system $[9,10]$.

Implicit in the definition of a set as a collection of entities of any sort is the use of at least two distinguishing criteria. One criterion indicates the common factor by which the set is distinguished; the other criterion distinguishes the elements of the set. As many different distinguishing criteria may be used as are deemed necessary or interesting. Different does not necessarily mean different in principle (qualitative difference) but can also be a quantitative difference (e.g. in size). Let each distinguishing criterion define a level. Of special interest is to consider if the various levels of distinction are related, and, if so, in what way. Let us call the relation of levels a hierarchy [11-14].

A hierarchy exists when there are levels or nested structures that may be distinguished, often requiring different descriptions at the different levels. For example, products in the Omniclass classification are components or assemblies of components for permanent incorporation into construction entities [8].

The system may be abstract or concrete, active or passive; dynamic or static, open (a system that allows cross-boundary exchange) or closed (a system that does not allow exchange across boundaries), simple or complex. 
From a functional point of view, a dynamic system achieves its goals by taking in energy/ information/resources, using or processing these elements, then expelling energy/information/ products that are different from the original inputs [15].

Complex systems express many subtle interrelations across data dimensions, space and time. Measuring the built environment is complex because of the large number of dimensions that could be assessed and because different features of the environment vary in importance by behavior [16]. Shifting units of analysis, as structural change proceeds, make theorizing difficult: 'Trying to generalize about the behaviour of a system that is mutating into a different system, either quickly or slowly, is not amenable to mathematical formalization in any deductive sense.' [17]

\subsection{Hierarchies}

It follows that a salient aspect of categorization is that any entity may belong to different, hierarchically organized categories [18]. It may be argued [19] that the correlational structure of entities in the world creates natural clusters, and that concepts correspond to these clusters. Entities are distributed as clusters, as groups of similar things. The mental representation of these categories takes the form of a prototype that summarizes the central tendency of the category (cluster). It seems as if there is one level of granularity at which these clusters stand out - the 'basic level'. Basic-level categories are the most inclusive categories that (a) possess numerous common attributes, (b) have similar shapes and (c) involve the same movements when interacted with. These basic-level clusters tend to be named across cultures and languages, for example 'floor' or 'house', correlating to the OmniClass 'Construction Entities by Function', which are significant, definable units of the built environment comprised of interrelated spaces and elements and characterized by function.

\subsection{The ontology of entities}

A discussion of the ontology of complex systems needs to address two main issues, the nature of their fundamental constituents or components and the nature of their internal features [20]. The second issue, that of system identity and boundaries, has been already been addressed. The first issue, however, requires further elaboration. More specifically, should the elements of the system under consideration be 'things' or 'processes'?

On the face of it, 'things' seem to be more amenable to analysis, but 'processes' more adequately reflect change over time. Once again, the choice depends on the objective of the analysis. Each approach has merit under certain conditions, similar to anatomy describing the structure of an organism and physiology describing the function.

Continuing the organism/built environment analogy: Biological and built systems share general design features: they display modularity, defined as the separability of the design into units that perform independently, at least to a first approximation This allows construction of extremely complex systems by using simple building blocks.

In a system representation, both the built environment and the ecosphere can be considered as complex, dynamic self-producing systems: "These systems exist in loose, nested hierarchies, each component system contained by the next level up and itself comprising a chain of linked subsystems at lower levels. The built environment as a self organizing system functions as a 'dissipative structure' requiring a continuous supply of available energy, material, and information necessary to produce and maintain its adaptive capacity and 
rejecting a continuous stream of degraded energy and waste back into the ecosystem (entropy)" [21].

\section{COMPLEXITY AND INTERDISCIPLINARITY}

\subsection{Complexity}

Complex systems contain multiple, interacting forces at different scales and temporal orders operating in diverse combinations in different particular situations [22].

'The interplay among hierarchical levels in nonlinear systems exhibiting complexity blur distinctions like part-whole, system-environment, constituent-level and so forth (e.g. cases where hierarchies are only distinguishable by differing time scales rather than by ontologically distinct features)...'. All these subtleties raise questions about identity and individuation for complex systems. For instance, can a complex system somehow be identified as a distinct individual from its environment? Can various hierarchies of a complex system be individuated from each other? Asking these questions presupposes both that a distinct entity can be identified as well as individuated from other entities [21]. Nor surprisingly, these questions are manifested in the built environment as well [23-27].

Complexity is often viewed as an objective characteristic of the structure of a system, defined and measured in terms of the number of its constituent parts, their diversity and relationships. However, it is often more informative to characterize complex systems phenomenologically $[28,29]$. One of the most important features in such a characterizations is observer relativity. The complexity of systems depends on how we observe and describe them. Measures of and judgments about complexity are not independent of the observer and his choice of measurement apparatus.

\subsection{Interdisciplinarity}

The presence of a basic system of ontological, epistemological, axiological, and methodological assumptions with which researchers approach their research is widely accepted [30].

In a study of overlapping thought in subjects, Hübenthal [31] exhorted that interdisciplinary collaboration is required because 'problems are much too complex to be judged appropriately, much less solved, merely with the subject-knowledge of a single discipline.' Similarly, in a debate about the relationship between interdisciplinary studies and complexity, it was proposed that interdisciplinarity is necessitated by complexity. It can be argued that the nature of complex systems '....provides a comprehensive rationale for interdisciplinary study, unifies the apparently divergent approaches, and offers guidance for criteria in each step of the integrative process. The ultimate objective of any interdisciplinary inquiry becomes understanding the portion of the world modeled by a particular complex system' [32].

\subsection{The web of knowledge}

Knowledge is not a monolithic structure, but rather a dynamic network or a web with multiple nodes of connection. "The metaphor of unity, with its accompanying values of universality and certainty, has been replaced by metaphors of plurality relationality in a complex world.' [32]. As mutual relations are reconsidered, new aggregate levels of organization are revealed and 'multidisciplinary' is becoming a common descriptor of research objects. 
The art of being a professional is becoming the art of managing complexity. As former ECB president, Jean-Claude Trichet, put it at the 2010 ECB flagship conference: 'The key lesson I would draw from our experience is the danger of relying on a single methodology or paradigm. Policy-makers need to have input from various theoretical perspectives and from a range of empirical approaches. Open debate and a diversity of views must be cultivated.' [33].

\section{CONCLUSIONS}

Conclusions to be drawn from the above relate to two areas: criteria for considering the built environment as a complex system and, second, methodology.

What conclusions can be drawn about which criteria are most appropriate for investigating the (complex) systems characteristics of built environment?

Firstly, and most saliently, the built environment is physical. Space, structure and materials are the physical criteria by which the built environment is distinguished. This is a common way in which construction information is classified, e.g. in the OmniClass ${ }^{\mathrm{TM}}$ Construction Classification System, distinctions are made between Entities by Form, Products, Materials and Properties.

The second important criterion is that of function: What is the purpose of the components of the built environment? In Omniclass terms these are Construction entities by function, Spaces by function and Elements.

The third criterion is the effect of the built environment on the human and natural environment. Here the focus of attention shifts: the original environment becomes the system of interest, and the original system of interest becomes the environment.

Lastly, two further criteria not discussed above but which also need to be considered are intention (why the building was built) and realization (the design, planning, costing, construction, management and the organization of the processes).

As far as methodology is concerned, it is evident that the built environment as a complex system cannot be fully described or explained by a single theory or fully investigated using a single approach [34], as complexity is "the property of a real world system that is manifest in the inability of any one formalism being adequate to capture all its properties." [35]

The reality being investigated consists of a nexus of phenomena that are not reducible to a single dimension. This implies that the research field is open and ill-defined, and that the elements under study as well as the relationships between them are context dependent [36].

This implies that a pluralist approach should be adopted when attempting to describe the built environment.

\section{REFERENCES}

[1] Rabeneck, A., A sketch-plan for construction of built environment theory. Building Research \& Information, 36(3), pp. 269-279, 2008. http://dx.doi.org/10.1080/09613210801928115

[2] Moffatt, S. \& Kohler, N., Conceptualizing the built environment as a social-ecological system. Building Research \& Information, 36(3), pp. 248-268, 2008. http://dx.doi.org/10.1080/09613210801928131

[3] Rapoport, A. (ed), The Mutual Interaction of People and their Built Environment: A Cross-cultural Perspective, Aldine, Chicago, IL, pp. 7-35, 1976. http://dx.doi.org/10.1515/9783110819052 
[4] Frank, L. \& Engelke, P., Multiple impacts of the built environment on public health: walkable places and the exposure to air pollution. International Regional Science Review, 2, pp. 193-216, 2005. http://dx.doi.org/10.1177/0160017604273853

[5] Carlson, C., Aytur, S., Gardner, K. \& Rogers, S., Complexity in built environment, health, and destination walking: a neighborhood-scale analysis. Journal of Urban Health, 89(2), pp. 270-284, 2012. http://dx.doi.org/10.1007/s11524-011-9652-8

[6] ISO 12006-2, "Building construction - Organization of information about construction works - Part 2: Framework for classification of information" also known as buildingSMART Data Dictionary or International Framework for Dictionaries (IFD) Library, 2015. More details in, available at: http://www.iso.org/iso/iso_catalogue/catalogue_tc/ catalogue_detail.htm?csnumber $=61753$

[7] ISO 12006-3, "Building construction - Organization of information about construction works - Part 3: Framework for object-oriented information" also known as buildingSMART Data Dictionary or International Framework for Dictionaries (IFD) Library, 2007.

[8] OCCS Development Committee, OCCS Net, The Omniclass Construction Classification System, available at: http://www. occsnet. org/.2002, (accessed 1 December 2002).

[9] Hall, A.D. \& Fagen, R.E., Definition of system. Revised introductory chapter: Systems Engineering, Bell Telephone Laboratories, N.Y. Reprinted in General Systems, 1, pp.18-28, 1956, and also in ed. W. Buckley, Modern Systems Research for the Behavioural Scientist. A Sourcebook, Chicago: Aldine, pp. 81-92, 1968.

[10] Rapoport, A., Modern systems theory - an outlook for coping with change. General Systems, 15, pp. 15-25, 1970.

[11] Pattee, H.H. (ed), Hierarchy Theory, New York: Braziller, 1973.

[12] Morowitz, H.J., The Emergence of Everything, Oxford University Press: Oxford, 2002.

[13] Batty, M., Cities and Complexity, MIT Press: Cambridge, 2007.

[14] Johnson, J., Cities: Systems of systems of systems. In Complexity Theories of Cities have Come of Age, eds J. Portugali, H. Meyer, E. Stolk \& E. Tan, Berlin: SpringerVerlag, 2012.

[15] Pulselli, R.M. \& Tiezzi, E., City Out of Chaos, Southampton: WIT Press, 2009.

[16] Glanz, K. \& Kegler, M.C., Environments: theory, research and measures of the built environment, 2009, available at: http://citeseerx.ist.psu.edu

[17] Foster, J., Economic systems. In Philosophy of Complex Systems. Vol. 10, Handbook of the Philosophy of Science, C. Hooker, Elsevier: Amsterdam, Oxford, 2011.

[18] Medin, D. \& Waxman, S.R., Conceptual organization. In A Companion to Cognitive Science, W. Bechtel \& G. Graham, Blackwell: Oxford, p. 168, 1999.

[19] Rosch, E., Mervis, C.B., Gray, W.D., Johnson, D.M. \& Boyes-Braem, P., Basic objects in natural categories. Cognitive Psychology, 8(3), pp. 382-439, 1976. http://dx.doi.org/10.1016/0010-0285(76)90013-X

[20] Hooker, C., Introduction to philosophy of complex systems. In Philosophy of Complex Systems. Vol. 10, Handbook of the Philosophy of Science, C. hooker, Elsevier: Amsterdam, Oxford, p. 867, 2011.

[21] Rees, W.E., Globalisation and sustainability. Conflict or convergence? Bulletin of Science, Technology and Society, 22(4), pp. 249-268, 2002. http://dx.doi.org/10.1177/0270467602022004001 
[22] Mitchell, S.D., Why integrative pluralism? E:CO Special Double Issue, 6(1-2), pp. 81-91, 2004.

[23] Allen, P.M., The importance of complexity for the research agenda in the built environment. Architectural Engineering and Design Management, 4(1), p. 5, 2008. http://dx.doi.org/10.3763/aedm.2008.S907

[24] Godfrey, P., Using systems thinking to learn to deliver sustainable built environments. Civil Engineering and Environmental Systems, 3, p. 219, 2010.

http://dx.doi.org/10.1080/10286608.2010.482656

[25] Müller, B., German Annual of Spatial Research and Policy 2010. Urban Regional Resilience: How Do Cities and Regions Deal with Change? Springer, Berlin: Heidelberg, 2011.

[26] Read, S., Meaning and material: Phenomenology, complexity, science and 'adjacent possible' cities. In Complexity Theories of Cities have Come of Age, J. Portugali, H. Meyer, E. Stolk \& E. Tan, Springer-Verlag: Berlin, 2012. http://dx.doi.org/10.1007/978-3-642-24544-2_7

[27] Williams, L.M., Getting to Know the Built Environment as a Complex System, Policy Paper, Wellesley Institute, Toronto, 2013.

[28] Fioretti, G. \& Visser, B., A cognitive interpretation of organizational complexity. E:CO Special Double Issue, 6(1-2), pp. 11-23, 2004.

[29] Vischer, J.C., Towards a user-centred theory of the built environment, Building Research \& Information, 36(3), pp. 231-240, 2008. http://dx.doi.org/10.1080/09613210801936472

[30] Vasilachis de Gialdino, I., Ontological and Epistemological Foundations of Qualitative Research [85 paragraphs]. Forum Qualitative Sozialforschung / Forum: Qualitative Social Research, 10(2), Art. 30, 2011, available at: http://nbn-resolving.de/ urn:nbn:de:0114-fqs0902307

[31] Hübenthal, U., Interdisciplinary thought. Issues in Integrative Studies, 12, pp. 55-75, 1994.

[32] Klein, J.T., Interdisciplinarity and complexity: An evolving relationship. E:CO Special Double Issue, 6(1-2), pp. 2-10, 2004.

[33] Jaeger, C., Mangalagiu, D. \& Mandel, A., Economics as a global system science. Complexity Economics, 2(1), pp. 1-3, 2013. http://dx.doi.org/10.7564/13-COEC21EDI

[34] Kellert, S.H., Longino, H.E. \& Waters, C.K. (eds), Scientific Pluralism. Vol XIX in Minnesota Studies in the Philosophy of Science, University of Minnesota Press, 2006.

[35] Mikulecky, D.C., The emergence of complexity: science coming of age or science growing old? Computers \& Chemistry, 25(4), pp. 341-348, 2001. http://dx.doi.org/10.1016/S0097-8485(01)00070-5

[36] Caetano, J.C., Curado, H. \& Jacquinet, M., On transdisciplinarity in organizations, innovation, and law. In Transdisciplinarity: Joint Problem-solving Among Science, Technology and Society. Workbook I: Dialogue Sessions and Idea Market, eds R. Häberli, R.W. Scholz, A. Bill \& M. Welti, Haffmans Sachbuch Verlag: Zürich, 1, pp. 528-533, 2000. 